DISTRIBUTION STATEMENT A. Approved for public release; distribution is unlimited.

\title{
Extracting Coherent Information from Noise Based Correlation Processing
}

\author{
W. A. Kuperman and W. S. Hodgkiss \\ Marine Physical Laboratory of the Scripps Institution of Ocenaography \\ Univeritiy of California, San Diego \\ La Jolla, CA 92093-0238 \\ phone: (858) 534-7990 fax: (858) 246-0182 email:wkuperman@ucsd.edu
}

Award Number: N00014-11-1-0125

\section{LONG-TERM GOALS}

The goal of this research is to establish methodologies to utilize ambient noise in the ocean and to determine what scenarios are best suited for applying these methods.

\section{OBJECTIVES}

Because noise-based correlation processing is based on equilibrium related stationary statistics, the ocean does not really provide a cooperatiing scenario for such processing. The objectives of this research is to develop array and signal processing that overcome the effects of the fluctuating ocean by essentilly developing techniques that speed up the processing to time scales shorter than those of ocean fluctuations.

\section{APPROACH}

The approach has been a combination of experiment/data analysis and the development of appropriate signal processing methods.

\section{WORK COMPLETED}

Reference $[1\}$ is an outgrowth of our noise correlation processing in which the acoustical structural and scattering properties of an object can be determined by noise measurements. Reference [2] is an outgrowth of our noise measurements originally originally taken from CTBTO arrays. Here the vector sensor emulation is extended to higher frequencies. The research referred to in Reference [3] is a spinoff from a fish tank experiment in which our noise correlation methods were applied to the buildings ambient vibrations in which the tank was located. We showed that we were able to determind the acoustical properties of tank from this ambient noise. This work has been reported in Reference [4]. Large at-sea experiments were conducted and the results will be analyized and reported on in the near future. 


\section{Report Documentation Page}

Form Approved

OMB No. 0704-0188

Public reporting burden for the collection of information is estimated to average 1 hour per response, including the time for reviewing instructions, searching existing data sources, gathering and maintaining the data needed, and completing and reviewing the collection of information. Send comments regarding this burden estimate or any other aspect of this collection of information,

including suggestions for reducing this burden, to Washington Headquarters Services, Directorate for Information Operations and Reports, 1215 Jefferson Davis Highway, Suite 1204, Arlington

VA 22202-4302. Respondents should be aware that notwithstanding any other provision of law, no person shall be subject to a penalty for failing to comply with a collection of information if it

does not display a currently valid OMB control number.

1. REPORT DATE

30 SEP 2014

4. TITLE AND SUBTITLE

Extracting Coherent Information from Noise Based Correlation

Processing

6. AUTHOR(S)

7. PERFORMING ORGANIZATION NAME(S) AND ADDRESS(ES)

University of California San Diego,Scripps Institution of Oceanography,9500 Gilman Drive,La Jolla,CA,92093

9. SPONSORING/MONITORING AGENCY NAME(S) AND ADDRESS(ES)

\section{DATES COVERED}

00-00-2014 to 00-00-2014

5a. CONTRACT NUMBER

5b. GRANT NUMBER

5c. PROGRAM ELEMENT NUMBER

5d. PROJECT NUMBER

5e. TASK NUMBER

5f. WORK UNIT NUMBER

8. PERFORMING ORGANIZATION REPORT NUMBER

10. SPONSOR/MONITOR'S ACRONYM(S)

11. SPONSOR/MONITOR'S REPORT NUMBER(S)

12. DISTRIBUTION/AVAILABILITY STATEMENT

Approved for public release; distribution unlimited

13. SUPPLEMENTARY NOTES

14. ABSTRACT

15. SUBJECT TERMS

16. SECURITY CLASSIFICATION OF:

a. REPORT

unclassified b. ABSTRACT unclassified c. THIS PAGE

unclassified
17. LIMITATION OF ABSTRACT

Same as

Report (SAR)
18. NUMBER 19a. NAME OF OF PAGES RESPONSIBLE PERSON

5 


\section{RESULTS}

We have worked out the theory of determining the scattering properties of an object by taking measurement of the body immersed in a random noise field. The theory is confiirmed with COMSOL finite element calculationsas shown in the eample figure for both the impedance matrices and the scattering.
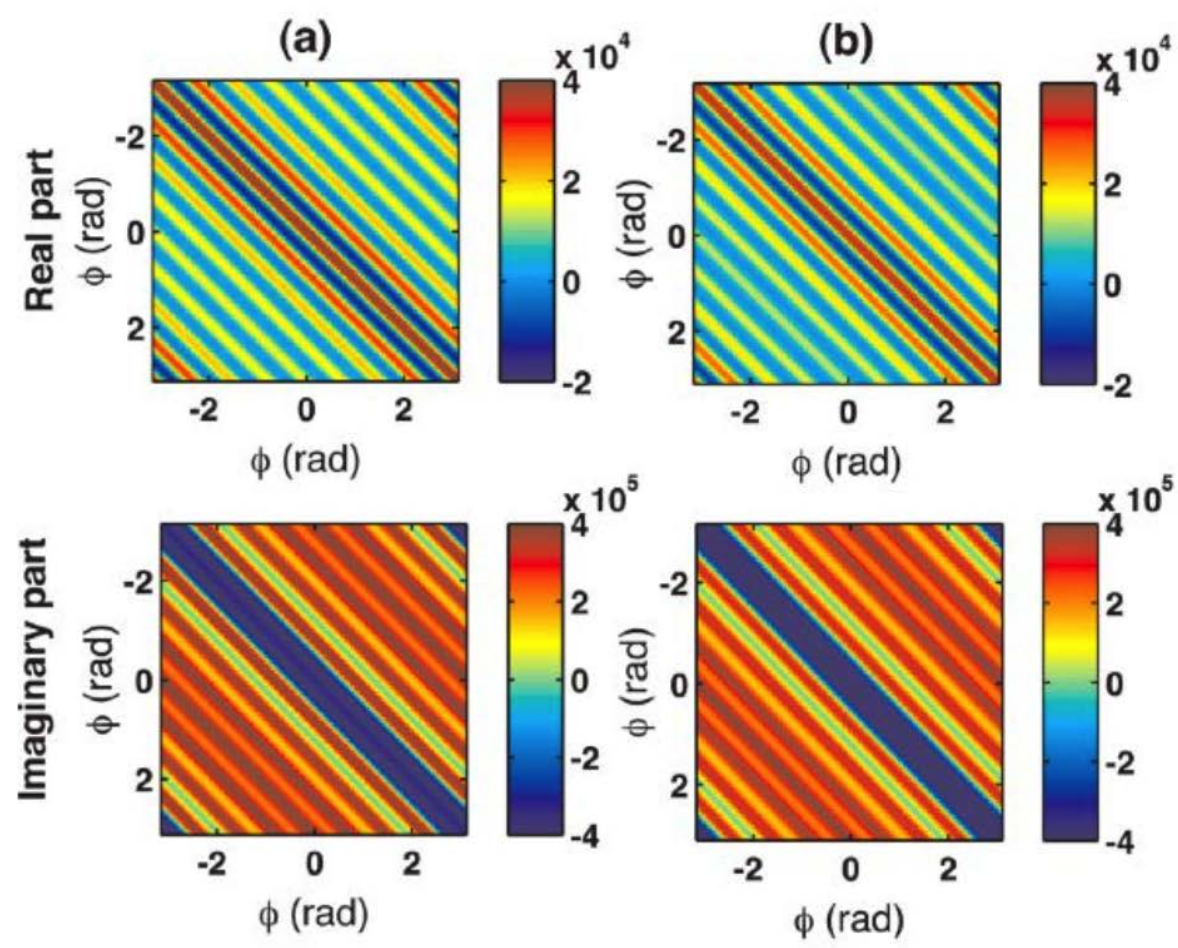

FIG. 4. (Color online) Structural impedance matrix $(\mathrm{Pa} \mathrm{s} / \mathrm{m})$ at 100 surface nodes for a lossy cylindrical shell with damping $\eta_{1}=0.05$. (a) Numerical result with pseudo-inversion of $\left\langle\mathbf{v p}^{H}\right\rangle$ performed with the 18 largest eigenvalues. (b) Analytical solution using nine modes.

\section{Figure 1}

We have recently done experiments on an instrumented shell that was produced by a 3D printer (a new experience for us). The shell was instrumented as shown in Figure 3 and the preliminary results confirm our theory. These will be reported in the future.

Finally, we have recently conducted at - sea experiments (see for example Figure 4) to measure the effect of fine scale oceanography on noise and propagation. Results will also be reported out after analysis. These also were opportunities for graduate students to participate in large scale ocean acoustic experiments. 

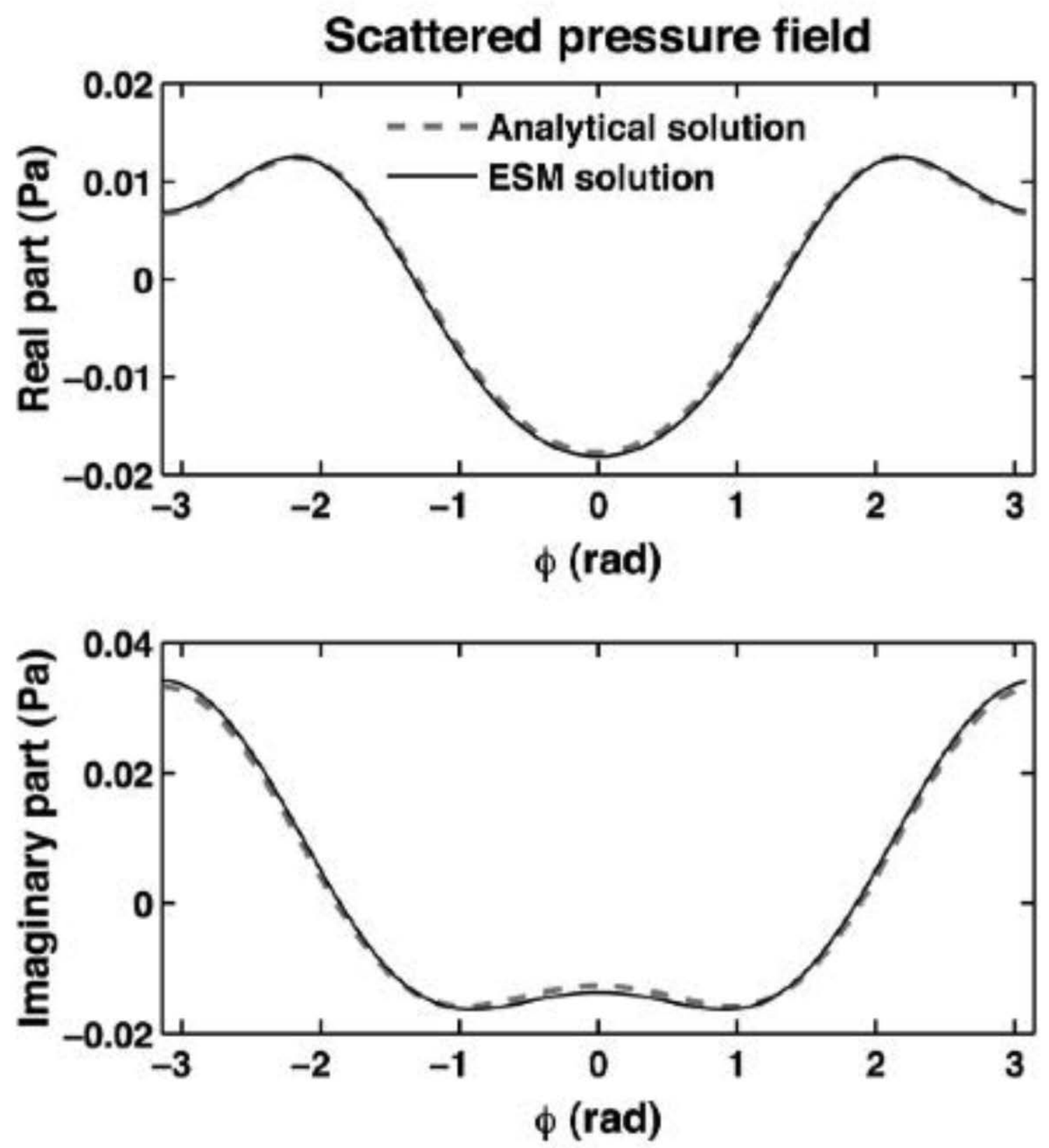

FIG. 6. Comparison of the scattered pressure fields from the equivalent source method (ESM) with the analytical solution when the cylindrical shell is excited by a $2 \mathrm{D}$ point source at $2 \mathrm{kHz}$. The point source is located at $3 \mathrm{~m}$ from the center of the shell. The scattered pressure field is plotted for receivers located all around the shell at $0.4 \mathrm{~m}$ from the center of the shell. The ESM solution uses 100 equivalent sources and the structural impedance matrix (Fig. 4) numerically evaluated using the correlation process.

Figure 2 


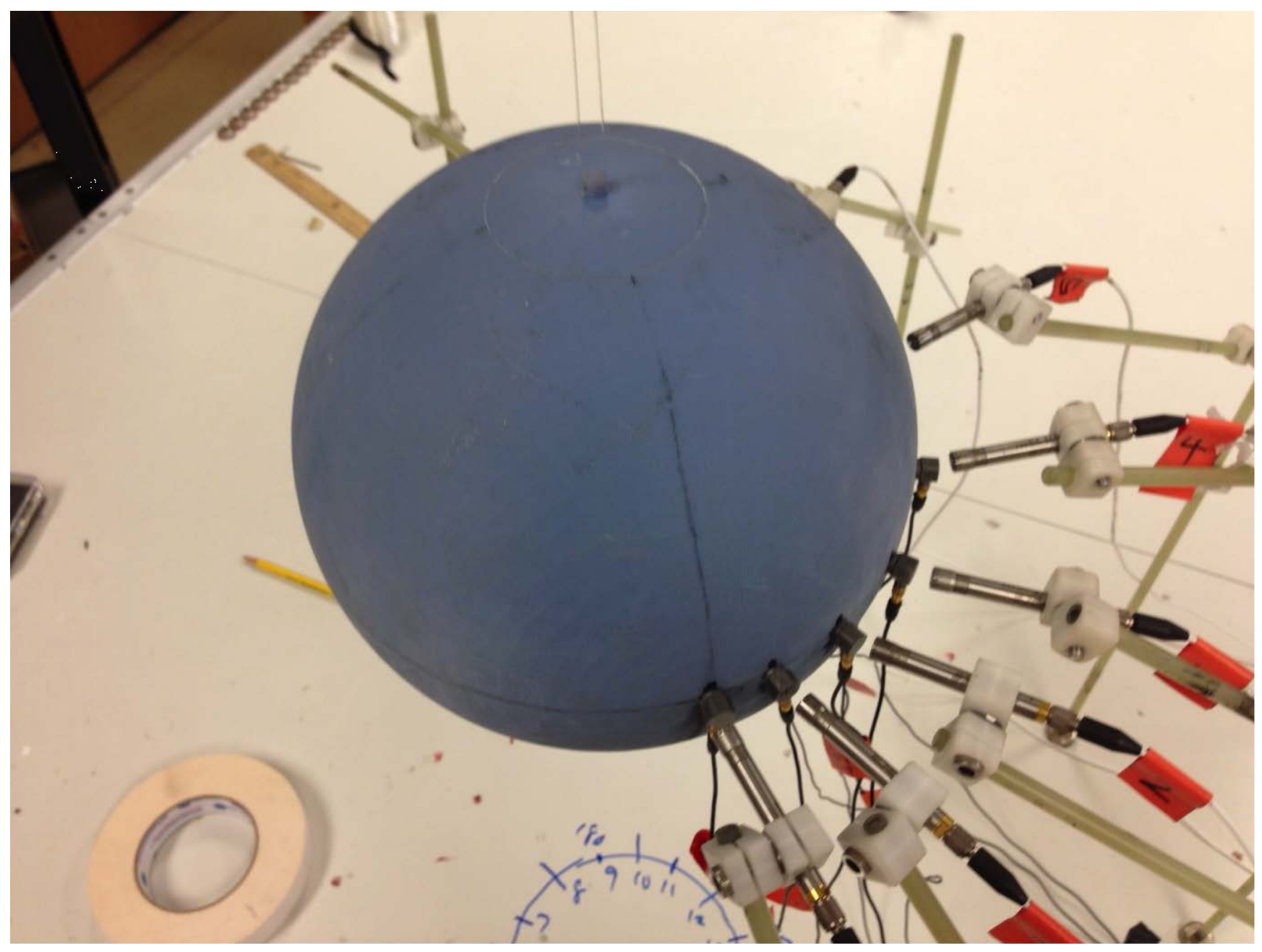

Figure 3

\section{IMPACT/APPLICATIONS}

The potential impact of this research is directed toward developing passive methods to study ocean environmental acoustics.

\section{RELATED PROJECTS}

None 

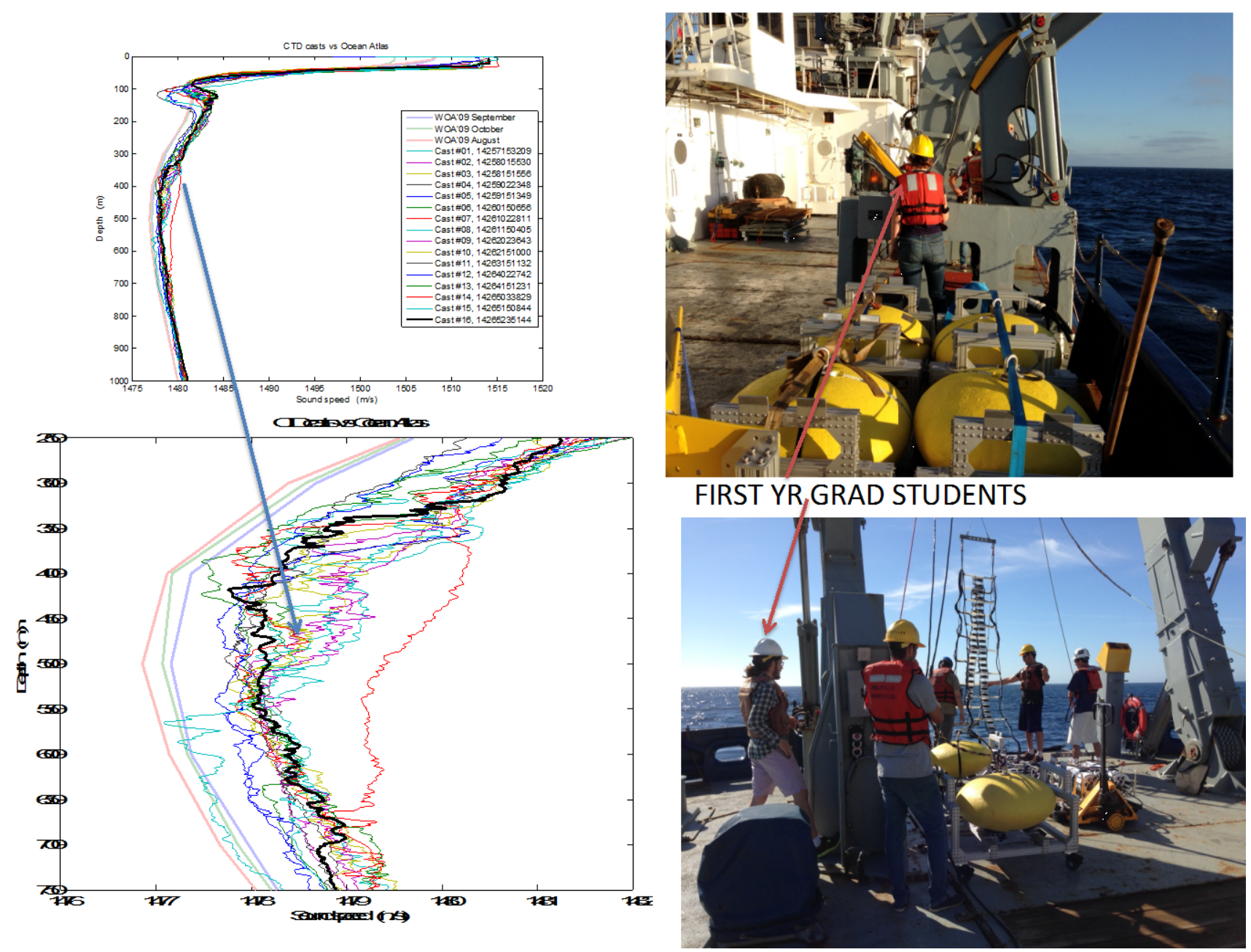

Figure 4

\section{PUBLICATIONS}

[1] "Prediction of a body's structural impedance and scattering properties using correlation of random noise,"Sandrine T. Rakotonarivo, W. A. Kuperman and Earl G. Williams, J. Acoust. Soc. Am. 134 , 4401 (2013) ; http://dx.doi.org/10.1121/1.4828833

[2] “Using hydrophones as vector sensors," Selda Yildiz, LeRoy M. Dorman, W. A. Kuperman, Karim Sabra, Philippe Roux, Dale Green, Stephanie Fried and Henrik Schmidt J. Acoust. Soc. Am. 135 , 2361 (2014) ; http://dx.doi.org/10.1121/1.4877778

[3] "Target localization through a data-based sensitivity kernel: A perturbation approach applied to a multistatic configuration." Selda Yildiz, Philippe Roux, Sandrine T. Rakotonarivo, Christian Marandet and W. A. Kuperman, J. Acoust. Soc. Am. 135 , 1800 (2014) ; http://dx.doi.org/10.1121/1.4868362

[4] "Model Tank Measurements and Using a Random Noise Feld to Determine the Scattering Properties of an Object." Sandrine Rakotonarivo, Selda Yildiz, Philippe Roux, Earl Williams, and W. A. Kuperman, Underwater Acoustics Measurements Conf, Rhodes 2014. 